\title{
Associations Between Mobile Health Technology use and Self-rated Quality of Life: A Cross-sectional Study on Older Adults with Cognitive Impairment
}

Gerontology \& Geriatric Medicine

\author{
Line Christiansen, MSc' ${ }^{1 D}$, Johan Sanmartin Berglund, MD, PhD', \\ Peter Anderberg, PhD ${ }^{1,2}$, Selim Cellek, MD, PhD³, \\ Jufen Zhang, $\mathrm{PhD}^{3}$, Evi Lemmens, $\mathrm{PhD}^{4}$, Maite Garolera, $\mathrm{PhD}^{5}$, \\ Fermin Mayoral-Cleries, MD, PhD $^{6}$, and Lisa Skär, PhD' $^{\prime}$
}

\begin{abstract}
Background: Quality of life (QoL) is affected even at early stages in older adults with cognitive impairment. The use of mobile health (mHealth) technology can offer support in daily life and improve the physical and mental health of older adults. However, a clarification of how mHealth technology can be used to support the QoL of older adults with cognitive impairment is needed. Objective: To investigate factors affecting mHealth technology use in relation to self-rated QoL among older adults with cognitive impairment. Methods: A cross-sectional research design was used to analyse mHealth technology use and QoL in I,082 older participants. Baseline data were used from a multi-centered randomized controlled trial including QoL, measured by the Quality of Life in Alzheimer's Disease (QoL-AD) Scale, as the outcome variable. Data were analyzed using logistic regression models. Results: Having moderately or high technical skills in using mHealth technology and using the internet via mHealth technology on a daily or weekly basis was associated with good to excellent QoL in older adults with cognitive impairment. Conclusions: The variation in technical skills and internet use among the participants can be interpreted as an obstacle for mHealth technology to support QoL.
\end{abstract}

\section{Keywords}

aging, cognitive impairment, gerontechnology, mobile health, quality of life

Manuscript received: December 2, 2020; final revision received: March 22, 2021; accepted: April 28, 2021.

\section{Introduction}

The movement toward mobile health (mHealth) technology to meet the needs of an aging population is widely discussed as beneficial (Changizi \& Kaveh, 2017; Sohaib Aslam et al., 2020). However, there are still concerns that need addressing before mHealth can meet its potential, which include examination of the ways in which digital health technologies can support health and quality of life (QoL) in older adults (Lupton, 2018; Marston et al., 2017). Concerning older adults with cognitive impairment, deterioration in memory, and other cognitive domains increases with age and affects QoL even at early stages (Bárrios et al., 2013; Winblad et al., 2016).

Longitudinal studies on the progression of cognitive impairment show that people with mild cognitive impairment are at higher risk of developing dementia, a multifactorial disorder known to be burdensome to older persons and their networks and a major cause of functional dependence, institutionalization, poor QoL, and mortality in older adults (Johansson et al., 2015; Prince

\footnotetext{
'Blekinge Institute of Technology, Karlskrona, Sweden

${ }^{2}$ University of Skövde, Sweden

${ }^{3}$ Anglia Ruskin University, Bishop Hall Lane, Chelmsford, UK

${ }^{4}$ University Colleges Leuven-Limburg, Genk, Belgium

${ }^{5}$ Brain, Cognition and Behavior-Clinical Research, Consorci Sanitari de Terrassa, Barcelona, Spain

${ }^{6}$ Regional University Hospital of Málaga, Spain
}

\section{Corresponding Author:}

Line Christiansen, Department of Health, Blekinge Institute of

Technology, Valhallavägen I, SE-37I 79 Karlskrona, Sweden.

Email: line.christiansen@bth.se 
et al., 2015; Qiu et al., 2013). There is an increasing number of studies suggesting that the adoption of mHealth technology can offer support in daily activities, relationships, memory, leisure activities, health, and safety; thus, it may improve the physical and mental health of older adults (Koo \& Vizer, 2019; Rathbone \& Prescott, 2017). However, according to previously published research, using the same source of information, the technology literacy level related to the use of mHealth technology has been shown to vary significantly among older adults with cognitive impairment, and there is a gap between the perceived potential and real use of these technologies (Christiansen et al., 2020; Guzman-Parra et al., 2020). In addition, the evidence for improving health and QoL with the use of mHealth technology among this study population is of limited quality; there is a lack of or inconsistency in data on health outcomes used for the evaluation of studies, little to no emphasis on user-centered design, study populations that are too small and so on (Bateman et al., 2017). What is obvious from the studies reported in the literature is that the relationship between mHealth technology and QoL has not yet been clarified. Determining this relationship contributes to bridging the knowledge gap of ways in which mHealth technology can be used to support QoL in older adults with cognitive impairment. Hence, the purpose of this study was to investigate factors affecting mHealth technology use in relation to self-rated QoL among older adults with cognitive impairment.

\section{Methods}

\section{Design and Setting}

A cross-sectional research design was used to investigate mHealth technology use and QoL among older adults with cognitive impairment. The present study used baseline data, collected between October 2017 and February 2019, from a multi-center randomized controlled trial-the Support, Monitoring and Reminder Technology for Mild Dementia project (SMART4MD; www.smart4md.eu; Anderberg et al., 2019). The trial was carried out in four clinical centers located as follows: one in Belgium, two in Spain, and one in Sweden. The objective of the trial was to investigate the effects of a customized mHealth application on the QoL of older adults with mild dementia or mild cognitive impairment and their caregivers. The application has been adapted specifically for this study population through a structured process involving the participation of primary users (adults with cognitive impairment) and informal caregivers. The protocol is registered at ClinicalTrials. gov (NCT03325699).

\section{Participants}

In total, 1,082 older participants were selected from the SMART4MD trial to be included in this study. The selection was based on the same inclusion criteria as used in the trial, where the participants needed to be aged 55 or above, have an informal caregiver, and have experienced difficulties in recall for the last 6 months. The participant also needed to score between 20 and 28 points on the Mini-Mental State Examination (MMSE) to be included. The MMSE contains questions regarding memory, learning, orientation, and so on; the possible score is 0 to 30 points, where a score of 26 points or less indicates cognitive difficulties (Folstein et al., 1975). In this study, a cut-off of 28 points was used based on findings that a cut-off score of 27 or 28 is appropriate to use in larger evaluations because adults in this context are at a greater risk of being diagnosed with dementia (O'Bryant et al., 2008). The median MMSE score for participants was 26 (interquartile range $[\mathrm{IQR}]=24-28)$ points, and $28.70 \% \quad(n=300)$ had received the formal diagnosis of dementia. Participants who scored 11 or above on the Geriatric Depression Scale or had a life expectancy of 3 years or less were excluded. This study sample has been included in a previous study (Guzman-Parra et al., 2020).

\section{Measures}

Outcome variable. To measure QoL as the outcome variable in this study, the Quality of Life in Alzheimer's Disease (QoL-AD) Scale was used (Logsdon et al., 1999). This is a disease-specific questionnaire, measuring the current QoL in individuals with cognitive impairment/dementia based on 13 items with a 4-point Likert scale, where the highest score responds to excellent QoL and the lowest score responds to poor QoL. The QoL$\mathrm{AD}$ is administered in an interview format where specific items have been selected to reflect Lawton's four domains of QoL in older adults. The internal reliability of the questionnaire was established in patients with AD and their caregivers' it was later found to be reliable and valid for individuals with MMSE scores $>10$ (Logsdon et al., 2002). In this study, the Cronbach's alpha for the QoL-AD index was calculated to be 0.886 , indicating good reliability. To establish the limit for poor to fair and good to excellent QoL among the study population, a cut-off on the 25th percentile (equal to a score of 32) in the QoL-AD index was used.

Variables. Sociodemographic characteristics such as age, sex, education level, and living arrangement was included to control for the main associations and whether the sample reflected the general population of this study or not. Cognitive status included the presence or absence of a formal diagnosis of dementia. To study mHealth technology use in relation to QoL, variables on access to the internet, self-assessed technical skills, frequency of usage, and attitude toward mHealth technology were included (Anderberg et al., 2019). These variables were used to assess the participants' perception of using mHealth technology and the inclusion were based on 
previous findings from a qualitative study and a feasibility study using the same sample (Christiansen et al., 2020; Quintana et al., 2020).

\section{Statistical Analysis}

All statistical analyses were performed using the Statistical Package for Social Science (SPSS), version 26.0 (IBM Corp., Armonk, NY). An initial descriptive analysis was conducted on the self-rated QoL in the QoL-AD, where the median value and the interquartile range (IQR) were calculated for the participants' response scores. When analyzing all the variables, the Chi-Square test and Mann-Whitney $U$-test were used in the comparison of poor to fair and good to excellent QoL. These results are presented as relative frequency $(\%)$ and absolute frequency $(N)$. To analyse the association between mHealth technology use and self-rated QoL, univariate analysis (i.e., correlations with Spearman's rho $\left[\mathrm{r}_{\mathrm{s}}\right]$ and binary logistic regression) and multivariate logistic regression models were performed. For model comparisons, the likelihood ratio (forward LR) was used in a stepwise selection based on the significance of the score statistic and on the probability. To determine how well the observed data corresponded to the predicted data in the models, the likelihood ratio test and goodness-of-fit test of Hosmer and Lemeshow (2013) was used. The results of the final multivariate logistic regression model are presented as odds ratios (ORs) with their 95\% confidence intervals (CIs) and $p$-values for statistical significance $(p<.05)$.

\section{Results}

In this study, the proportions of gender and age were similar, where $53.10 \%(N=575)$ were women, with a median age of $75(\mathrm{IQR}=70-79)$ years, and $46.90 \%$ $(N=507)$ were men, with a median age of $75(\mathrm{IQR}=71-$ 79) years. In the study sample, the proportions of participants with good to excellent and poor to fair QoL, as assessed using the QoL-AD, were 76.60\% $(N=796)$ and $26.40 \%(N=286)$, respectively.

\section{Self-rated QoL based on Different QoL Aspects}

The median QoL score assessed by the QoL-AD among the study sample was $36.00(\mathrm{IQR}=32.00-40.00)$, indicating a good QoL. The median score was slightly higher in men $(38.00, \mathrm{IQR}=34.00-41.00)$ than it was in women (36.00, IQR $=31.00-39.00)$. Most participants reported that they had a good relationship with their spouse $(3.00, \mathrm{IQR}=3.00-4.00)$, family members $(3.00$, $\mathrm{IQR}=3.00-4.00)$, and friends $(3.00, \mathrm{IQR}=3.00-3.00)$ and felt they had a good living situation (3.00, $\mathrm{IQR}=3.00-4.00)$. The lowest median value of QoL was observed for the participants' self-rated memory, where most reported having either poor or fair memory $(2.00$, $\mathrm{IQR}=1.00-3.00)$.

\section{Relationship Between mHealth Technology use and QoL}

As shown in Table 1, the greatest proportions of participants who reported poor to fair QoL had the following characteristics: female sex $(64.40 \%, N=184)$, age of 65-74 years $(40.60 \%, N=116)$, completion of elementary school $(72.90 \%, N=207)$ and previous diagnosis of dementia $(35.80 \%, N=98)$. Among those who reported good to excellent QoL, higher responses were observed in terms of higher education level $(22.80 \%, N=181)$, technical skills in using mHealth technology $(26.10 \%$, $N=208$ ) and frequency of using the internet with mHealth technology $(38.20 \%, N=304)$. As a coherent perception, most participants had a positive attitude toward using mHealth technology for memory support $(75.80 \%, N=820)$.

In the logistic regression analysis, univariate analysis showed weak correlations with attitudes toward mHealth $\left(r_{s}=0.07, p=.02\right)$, access to the internet $\left(r_{s}=0.07\right.$, $p=.04)$, frequency of using the internet with mHealth technology $\left(r_{s}=0.11, p<.001\right)$ and technical skills in using mHealth technology $\left(r_{s}=0.18, p<.001\right)$. In the multivariate analysis, two of the mHealth variables was found to be associated with QoL (Table 2). Those who reported having moderately or high technical skills in using mHealth technology had $127 \%(\mathrm{OR}=0.44)$ higher odds of having good to excellent QoL than those who reported having no or low technical skills. Further, those who reported using the internet daily or weekly with mHealth technology had 55\% $(\mathrm{OR}=0.65)$ higher odds of having good to excellent QoL than those who rarely or never used the internet.

Overall, the multivariate logistic regression analysis resulted in a model that explains $15 \%$ of the variation in the incidence of having good to excellent QoL (Table 2). The rate of having good to excellent QoL was 60\% $(\mathrm{OR}=0.62)$ higher among men than women and increased with age $(\mathrm{OR}=2.60-6.51)$. Those who had completed higher education had $99 \%(\mathrm{OR}=0.50)$ higher odds of having good to excellent QoL compared with those who completed elementary school.

\section{Discussion}

This study aimed to investigate factors affecting mHealth technology use in relation to self-rated QoL among older adults with cognitive impairment. The results showed that the self-rated QoL among the study sample was generally perceived as good, but poorer QoL was reported in relation to the participants' selfrated memory. As demonstrated in the analysis, those diagnosed with dementia had a poorer QoL. Despite this, cognitive status (i.e., diagnosis of dementia) was 
Table I. Distribution of Variables by Self-Rated QoL among Older Adults with Cognitive Impairment $(N=1,082)$.

\begin{tabular}{|c|c|c|c|c|}
\hline & Good/excellent QoL & Poor/fair QoL & Total & \\
\hline Variable & $N(\%)$ & $N(\%)$ & $N(\%)$ & $p$-Value ${ }^{a, b}$ \\
\hline \multicolumn{4}{|l|}{ Gender } & $.00^{\mathrm{a}}$ \\
\hline Male & $405(50.90)$ & $102(35.70)$ & $507(46.90)$ & \\
\hline Female & $391(49.10)$ & $184(64.30)$ & $575(53.10)$ & \\
\hline \multicolumn{4}{|l|}{ Age groups } & $.00^{\mathrm{b}}$ \\
\hline $55-64$ & $49(6.20)$ & $49(17.10)$ & $98(9.10)$ & \\
\hline $65-74$ & $312(39.20)$ & $116(40.60)$ & $428(39.60)$ & \\
\hline $75-84$ & $37 \mid(46.60)$ & $108(37.80)$ & $479(44.30)$ & \\
\hline $85+$ & $64(8.00)$ & $13(4.50)$ & $77(7.10)$ & \\
\hline \multicolumn{4}{|l|}{ Education level $(n=1,077)$} & $.00^{\mathrm{b}}$ \\
\hline Elementary school & $439(55.40)$ & $207(72.90)$ & $646(60.00)$ & \\
\hline Secondary school & $173(21.80)$ & $51(18.00)$ & $224(20.80)$ & \\
\hline Higher education & I8I (22.80) & $26(9.20)$ & $207(19.20)$ & \\
\hline \multicolumn{4}{|l|}{ Living arrangement $(n=1,074)$} & $.55^{\mathrm{a}}$ \\
\hline Living with others & $625(79.10)$ & $230(81.00)$ & $855(79.60)$ & \\
\hline Living alone & $165(20.90)$ & $54(19.00)$ & $219(20.40)$ & \\
\hline \multicolumn{4}{|l|}{ Diagnosis of dementia $(n=1,045)$} & $.00^{\mathrm{a}}$ \\
\hline Yes & $202(26.20)$ & $98(35.80)$ & $300(28.70)$ & \\
\hline No & $569(73.80)$ & $176(64.20)$ & 745 (7I.30) & \\
\hline \multicolumn{4}{|l|}{ Access to internet $(n=1,0 \mid 3)$} & $.04^{\mathrm{a}}$ \\
\hline Yes & $565(74.20)$ & I $70(67.50)$ & $735(72.60)$ & \\
\hline No & $196(25.80)$ & $82(32.50)$ & $278(27.40)$ & \\
\hline \multicolumn{4}{|l|}{ Frequency of using mHealth technology } & $.14^{\mathrm{b}}$ \\
\hline Daily & $448(56.30)$ & I $44(50.30)$ & $592(54.70)$ & \\
\hline Weekly & $65(8.20)$ & $31(10.80)$ & $96(8.90)$ & \\
\hline Rarely & $21(2.60)$ & $8(2.80)$ & $29(2.70)$ & \\
\hline Never & $262(32.90)$ & $103(36.00)$ & $365(33.70)$ & \\
\hline \multicolumn{4}{|c|}{ Frequency of using the internet with mHealth technology } & $.002^{\mathrm{b}}$ \\
\hline Daily & $304(38.20)$ & $76(26.60)$ & $380(35.10)$ & \\
\hline Weekly & $71(8.90)$ & $23(8.00)$ & $94(8.70)$ & \\
\hline Rarely & $4 \mathrm{I}(5.20)$ & $28(9.80)$ & $69(6.40)$ & \\
\hline Never & $380(47.70)$ & $159(55.60)$ & $539(49.80)$ & \\
\hline \multicolumn{4}{|l|}{ Technical skills in using mHealth technology } & $.00^{\mathrm{b}}$ \\
\hline None & $278(34.90)$ & | 3 | (45.80) & $409(37.80)$ & \\
\hline Low & $268(33.70)$ & $118(41.30)$ & $386(35.70)$ & \\
\hline Moderately & $208(26.10)$ & $34(11.90)$ & $242(22.40)$ & \\
\hline High & $42(5.30)$ & $3(1.00)$ & $45(4.10)$ & \\
\hline \multicolumn{4}{|l|}{$\mathrm{mHealth}$ technology for memory support } & $.60^{\mathrm{a}}$ \\
\hline Yes & $155(19.50)$ & $51(17.80)$ & $206(19.00)$ & \\
\hline No & $64 \mid(80.50)$ & $235(82.20)$ & $876(81.00)$ & \\
\hline \multicolumn{4}{|l|}{ App/software for memory support } & $.73^{\mathrm{a}}$ \\
\hline Yes & $79(9.90)$ & $26(9.10)$ & $105(9.70)$ & \\
\hline No & $717(90.10)$ & $260(90.90)$ & $977(90.30)$ & \\
\hline \multicolumn{4}{|c|}{ Attitude toward mHealth technology for memory support } & $.02^{\mathrm{a}}$ \\
\hline Positive & $618(77.60)$ & $202(70.60)$ & $820(75.80)$ & \\
\hline Negative & $178(22.40)$ & $84(29.40)$ & $262(24.20)$ & \\
\hline
\end{tabular}

Note. Significance level $p<.05$.

aPearson Chi-square.

bMann-Whitney U-test.

not included in the final model due to correlations with the mHealth variables. These results are in line with previous research that used the QoL-AD Scale, clarifying that QoL ratings by people with mild dementia are influenced by a variety of factors; thus, QoL cannot be determined by a single aspect, such as cognitive status (Woods et al., 2014). Since the measurement of QoL in this study is relevant both in relation to the participants' condition and to the use of mHealth technology, the results must be considered from a multi-dimensional 
Table 2. Multivariate Logistic Regression Analysis (Forward: LR). Impact of mHealth Technology Use on Self-Rated QoL $(N=1,077)$.

\begin{tabular}{|c|c|c|c|}
\hline $\begin{array}{l}\text { Coefficient OR } \\
\left(e^{b}\right)\end{array}$ & & $95 \% \mathrm{Cl}$ for OR & $p$-Value \\
\hline Constant & 5.04 & - & 0 \\
\hline \multicolumn{4}{|l|}{ Gender } \\
\hline Male & Ref. & & \\
\hline Female & 0.62 & $0.46-0.86$ & 0 \\
\hline \multicolumn{4}{|l|}{ Age groups } \\
\hline $55-64$ & Ref. & & \\
\hline $65-74$ & 2.6 & $1.57-4.30$ & 0 \\
\hline $75-84$ & 4.79 & $2.82-8.14$ & 0 \\
\hline $85+$ & 6.51 & $2.85-14.85$ & 0 \\
\hline \multicolumn{4}{|l|}{ Education level } \\
\hline Elementary school & 0.5 & $0.3 \mathrm{I}-0.82$ & .01 \\
\hline Secondary school & 0.74 & $0.42-1.31$ & .3 \\
\hline Higher education & Ref. & & \\
\hline \multicolumn{4}{|c|}{ Technical skills in using mHealth technology } \\
\hline None/low & 0.44 & $0.28-0.69$ & 0 \\
\hline Moderately/high & Ref. & & \\
\hline \multicolumn{4}{|c|}{ Frequency of using internet with mHealth technology } \\
\hline Daily/weekly & Ref. & & \\
\hline Rarely/never & 0.65 & $0.44-0.94$ & .02 \\
\hline Test & & $\chi^{2}$ & p-Value \\
\hline \multicolumn{4}{|l|}{ Overall model evaluation } \\
\hline Likelihood ratio test & & 103.93 & 0 \\
\hline \multicolumn{4}{|l|}{ Goodness-of-fit test } \\
\hline Hosmer and Lemeshow & & 4.07 & .77 \\
\hline
\end{tabular}

Note. Cox and Snell $R^{2}=0.10$. Nagelkerke's $R^{2}=0.15$. QoL = quality of life is dichotomized (good/excellent $Q o L=$ reference).

perspective, which includes micro (individual, subjective) and macro (societal, objective) perspectives on QoL (i.e., Bowling, 2017).

From a micro perspective, the results of this study showed that technical skills and frequency of using the internet was associated with the self-rated QoL, where moderately to high technical skills and daily or weekly internet use corresponded to the perception of having a good or excellent QoL among the older adults. Despite this, many considered that they had low technical skills in using mHealth technology, and almost half of the study sample reported that they never used the internet with mHealth technology. The proportion of daily internet use through mobile technology among individuals aged 16-74 years in Europe was 73\% at the beginning of 2019, where Belgium, Spain, and Sweden recorded some of the highest proportions of mobile internet use (Eurostat, 2020). Previous research shows that selfassessed abilities and computer/internet skills among older adults are predictive of willingness to adopt technologies (Berkowsky et al., 2017). Studies also indicate that the use of the internet, especially online cognitive training programmes, may have a positive effect on cognitive functions in older adults (Berner et al., 2019; Klimova, 2016). However, using the internet via mHealth technology requires a range of cognitive and technical abilities, such as information-processing speed and working memory performance. In older adults with cognitive impairment, these cognitive abilities are usually reduced, which can negatively affect their use of and interaction with user interfaces (Kwon, 2017; Marston et al., 2017).

Although most older adults in this study had a positive attitude toward using mHealth technology to support memory, the variation in their technical skills, and internet usage indicates that the technology needs to be adapted. Admittedly, this result can be considered as a technology-related cohort effect, as older adults in the future will probably use different types of ICT to an increasing extent, including mHealth technology, to support functions in their daily lives, and maintain social networks. Regardless, a generational gap in capabilities will likely always remain (Damant \& Knapp, 2015).

From a macro perspective, the results showed that the self-rated QoL was associated with gender, age, and level of education. The perception of having a good to excellent QoL was significantly higher among males, those with a higher age and those who had completed higher education. The gender differences in QoL among the study sample are probably linked to the level of education. For many years, men have had a higher level of education than women, which is mirrored in this study sample. In addition, higher levels of education are associated with better cognitive performance (Shuba \& 
Prakash, 2017). Regarding gender differences in technology use, research shows that men are more likely to use and access various types of information and communication technology (ICT) than women are (Kim et al., 2017). Research also shows that internet use in old age predicts a smaller cognitive decline only in men (Ihle et al., 2020). Nevertheless, research on the gender differences in mHealth technology use among older adults with cognitive impairment is still limited.

The results of a higher QoL with increased age may be explained by respondents' living circumstances. Since most participants reported having a good living situation, where $79.60 \%$ lived with their spouse, children or someone else, they had social interaction; previous studies identified social interaction as important for the perception of having a good QoL among older adults with mild cognitive impairment (Beerens et al., 2016; Christiansen et al., 2020). In addition, a socially integrated lifestyle in old age, along with mental and physical activity, can have a beneficial effect on cognition that may protect against dementia (Fratiglioni et al., 2004). Overall, the findings from this study contributes with knowledge of importance to the design of mHealth technology for older adults with cognitive impairment by showing ways of using mHealth technology. For the use of mHealth technology to support QoL in older adults with cognitive impairment, future intervention research must be responsive to the needs and capabilities of these older adults.

\section{Limitations}

Since this study used a cross-sectional design, in which observed data were collected at a specific point in time, a causal relationship between mHealth technology use and QoL cannot be established. However, the use of a cut-off point for assessing QoL revealed valuable information on the variation in QoL within the study sample at baseline, which is of importance for future research when evaluating longitudinal effects of mHealth technology on QoL in older adults with cognitive impairment.

Further, the inclusion of variables on mHealth technology use in this study were limited to some of the technology use factors for this population which may have affect the final outcome model. However, there may be other factors such as general health status and financial support affecting the relationship between selfrated QoL and mHealth technology use than those included in this study. Also, the use of a disease-specific instrument to measure the outcome among a study sample in the intermediate stage between healthy aging with minor cognitive deficits and dementia can be regarded as a limitation on the validity of the results in this study. However, the inclusion of a rather large sample where almost $30 \%$ of the respondents had been diagnosed with dementia, and given that the respondents' cognitive status is likely to deteriorate (Faria et al., 2018), the chosen instrument is considered valid for this study sample.

\section{Conclusions}

Factors affecting mHealth technology use in relation to self-rated QoL among older adults with cognitive impairment involves sociodemographic factors, technical skills and internet use. Using mHealth technology can support QoL in older adults with cognitive impairment provided they have adequate technical skills to use the internet regularly. However, the variation in technical skills and internet use among these older adults seems to constitute an obstacle for mHealth technology to support QoL among this population. To facilitate the use and increase the adoption of mHealth technology among older adults with cognitive impairment, we recommend that future development and design of mHealth technologies be based on a participatory approach where older adults with cognitive impairment are integrated into the innovation process.

The findings from this study have implications for future evaluations of mHealth interventions aiming at supporting the QoL in older adults with cognitive impairment, mainly by demonstrating aspects that are important for mHealth technology use to contribute to an improved QoL, as well as by showing the variation of QoL within this population.

\section{Acknowledgments}

The authors acknowledge all the older adults who volunteered to participate in the SMART4MD project. This work is a collaboration between several members of the SMART4MD consortium (see www.smart4md.eu). The consortium acknowledges the valuable contributions to the project of the following past and present members not reaching full ICMJE standards for authorship in this manuscript: Karen Hayden, Tony Fenton, Claire Preston, Tomer Regev and Stephen Moore (Anglia Ruskin University, UK); Dominique Manhaeve and Jessie Schrijvers (University Colleges LeuvenLimburg, Belgium); María Teresa Arredondo Waldmeyer and Rebeca I. García-Betances (Universidad Politécnica de Madrid, UPM, Spain); Ifty Ahmed (Healthbit Ltd, UK); Carmen Sanmartin, Eric Piculell, Joakim Frögren and Doris Bohman (Blekinge Institute of Technology, Sweden); Jose Guzman and Pilar Barnestein Fonseca (Research Unit, La Unidad de Gestión Clínica de Mental Health, Instituto de Investigación Biomédica de Málaga, Hospital Regional Universitario Málaga, Málaga, Spain); Maria Quintana Aparicio (Brain, Cognition and Behavior-Clinical Research, Consorci Sanitari de Terrassa, Barcelona, Spain). In addition, we would like to thank the statistician Linda Abrahamsson, who assisted in the statistical analysis.

\section{Declaration of Conflicting Interests}

The author(s) declared no potential conflicts of interest with respect to the research, authorship, and/or publication of this article.

\section{Funding}

The author(s) disclosed receipt of the following financial support for the research, authorship, and/or publication of this article: This work was supported by Blekinge Institute of 
Technology and the Support, Monitoring and Reminder Technology for Mild Dementia (SMART4MD) project, which is financially supported by the European Commission Horizon 2020 Research and Innovation Programme [Grant No. 643399].

\section{Ethical Considerations}

The study was performed in compliance with the ethical guidelines of the Declaration of Helsinki (World Medical Association, 2013). The SMART4MD study has been approved by local ethical committees in Belgium (No. S60852) and Spain (No. 02-16-107-029) and the Regional Ethical Review Board in Sweden (LU No. 650-00 and No. 744-00). The older adults were provided both written and oral information about the trial and its content before written informed consent was obtained from each participant entering the trial.

\section{ORCID iDs}

Line Christiansen (iD https://orcid.org/0000-0002-5135-0452 Peter Anderberg (iD https://orcid.org/0000-0001-9870-8477

\section{References}

Anderberg, P., Barnestein-Fonseca, P., Guzman-Parra, J., Garolera, M., Quintana, M., Mayoral, F., Lemmens, E., \& Berglund, J. S. (2019). Support Monitoring and Reminder Technology for Mild Dementia (SMART4MD) effects of a digital platform adapted specifically for persons with mild cognitive impairment: Study protocol for a pilot randomized controlled trial. JMIR Research protocols, 8(6), e13711. https://doi.org/10.2196/13711

Bárrios, H., Narciso, S., Guerreiro, M., Maroco, J., Logsdon, R., \& de Mendonça, A. (2013). Quality of life in patients with mild cognitive impairment. Aging \& Mental Health, 17(3), 287-292. https://doi.org/10.1080/13607863.2012.7 47083

Bateman, D. R., Srinivas, B., Emmett, T. W., Schleyer, T. K., Holden, R. J., Hendrie, H. C., \& Callahan, C. M. (2017). Categorizing health outcomes and efficacy of mHealth apps for persons with cognitive impairment: A systematic review. Journal of Medical Internet Research, 19(8), e301. https://doi.org/10.2196/jmir.7814

Beerens, H. C., de Boer, B., Zwakhalen, S. M. G., Tan, F. E. S., Ruwaard, D., Hamers, J. P. H., \& Verbeek, H. (2016). The association between aspects of daily life and quality of life of people with dementia living in long-term care facilities: A momentary assessment study. International Psychogeriatrics, 28(8), 1323-1331. https://doi.org/10. 1017/S1041610216000466

Berkowsky, R. W., Sharit, J., \& Czaja, S. J. (2017). Factors predicting decisions about technology adoption among older adults. Innovation in Aging, 1(3), 1-12. https://doi. org/10.1093/geroni/igy002

Berner, J., Comijs, H., Elmståhl, S., Welmer, A.-K., Sanmartin Berglund, J., Anderberg, P., \& Deeg, D. (2019). Maintaining cognitive function with internet use: A two-country, six-year longitudinal study. International Psychogeriatrics, 31(7), 929-936. https:// doi.org/10.1017/S1041610219000668

Bowling, A. (2017). Measuring Health: A review of subjective health, well-being and quality of life measurement scales (4th ed.). Open University Press.
Changizi, M., \& Kaveh, M. H. (2017). Effectiveness of the mHealth technology in improvement of healthy behaviors in an elderly population-A systematic review. MHealth, 3(51), 1-9. https://doi.org/10.21037/mhealth.2017.08.06

Christiansen, L., Lindberg, C., Sanmartin Berglund, J., Anderberg, P., \& Skär, L. (2020). Using mobile health and the impact on health-related quality of life: Perceptions of older adults with cognitive impairment. International Journal of Environmental Research and Public Health, 17(8), e2650. https://doi.org/10.3390/ijerph17082650

Damant, J., \& Knapp, M. (2015). What are the likely changes in society and technology which will impact upon the ability of older adults to maintain social (extra-familial) networks of support now, in 2025 and in 2040? [Monograph]. Government Office for Science, UK. https://www.gov.uk/ government/organisations/government-office-for-science

Eurostat. (2020). Digital economy and society statistics Households and individuals [Dataset]. https://ec.europa. eu/eurostat/statistics-explained/index.php?title=Digital_ economy_and_society_statistics_-_households_and_ individuals\#Internet_usage

Faria, C. A., Alves, H. V. D., Barbosa, E. N. B. E., \& CharchatFichman, H. (2018). Cognitive deficits in older adults with mild cognitive impairment in a two-year follow-up study. Dementia \& Neuropsychologia, 12(1), 19-27. https://doi. org/10.1590/1980-57642018dn12-010003

Folstein, M. F., Folstein, S. E., \& McHugh, P. R. (1975). "Mini-mental state". A practical method for grading the cognitive state of patients for the clinician. Journal of Psychiatric Research, 12(3), 189-198. https://doi.org/ sjöstrm

Fratiglioni, L., Paillard-Borg, S., \& Winblad, B. (2004). An active and socially integrated lifestyle in late life might protect against dementia. The Lancet Neurology, 3(6), 343-353. https://doi.org/10.1016/S1474-4422(04) 00767-7

Guzman-Parra, J., Barnestein-Fonseca, P., Guerrero-Pertiñez, G., Anderberg, P., Jimenez-Fernandez, L., ValeroMoreno, E., Goodman-Casanova, J. M., Cuesta-Vargas, A., Garolera, M., Quintana, M., García-Betances, R. I., Lemmens, E., Sanmartin Berglund, J., \& Mayoral-Cleries, F. (2020). Attitudes and use of information and communication technologies in older adults with mild cognitive impairment or early stages of dementia and their caregivers: Cross-sectional study. Journal of Medical Internet Research, 22(6), e17253. https://doi.org/10.2196/17253

Hosmer, D. W., \& Lemeshow, S. (2013). Applies logistic regression. Wiley.

Ihle, A., Bavelier, D., Maurer, J., Oris, M., \& Kliegel, M. (2020). Internet use in old age predicts smaller cognitive decline only in men. Scientific Reports, 10(1), 8969. https://doi.org/10.1038/s41598-020-65846-9

Johansson, M. M., Marcusson, J., \& Wressle, E. (2015). Cognitive impairment and its consequences in everyday life: Experiences of people with mild cognitive impairment or mild dementia and their relatives. International Psychogeriatrics/IPA, 27(6), 949-958. https://doi. org $/ 10.1017 / \mathrm{S} 1041610215000058$

Kim, J., Lee, H. Y., Christensen, M. C., \& Merighi, J. R. (2017). Technology access and use, and their associations with social engagement among older adults: Do women and men differ? The Journals of Gerontology: Series B, 72(5), 836-845. https://doi.org/10.1093/geronb/gbw123 
Klimova, B. (2016). Use of the internet as a prevention tool against cognitive decline in normal aging. Clinical Interventions in Aging, 11, 1231-1237. https://doi. org/10.2147/CIA.S113758

Koo, B. M., \& Vizer, L. M. (2019). Examining mobile technologies to support older adults with dementia through the lens of personhood and human needs: Scoping review. JMIR MHealth and UHealth, 7(11), e15122. https://doi. org/10.2196/15122

Kwon, S. (2017). Gerontechnology: Research, practice, and principles in the field of technology and aging. Springer Publishing Company.

Logsdon, R. G., Gibbons, L. E., McCurry, S. M., \& Teri, L. (1999). Quality of life in Alzheimer's disease: Patient and caregiver reports. Journal of Mental Health and Aging, 5(1), 21-32.

Logsdon, R. G., Gibbons, L. E., McCurry, S. M., \& Teri, L. (2002). Assessing quality of life in older adults with cognitive impairment. Psychosomatic Medicine, 64(3), 510-519. https://doi.org/10.1097/00006842-20020500000016

Lupton, D. (2018). Digital health: Critical and cross-disciplinary perspectives. Routledge.

Marston, H. R., Freeman, S., \& Musselwhite, C. (Eds.). (2017). Mobile e-Health. Springer International Publishing.

O’Bryant, S. E., Humphreys, J. D., Smith, G. E., Ivnik, R. J., Graff-Radford, N. R., Petersen, R. C., \& Lucas, J. A. (2008). Detecting dementia with the Mini-Mental State Examination (MMSE) in highly educated individuals. Archives of Neurology, 65(7), 963-967. https://doi. org/10.1001/archneur.65.7.963

Prince, M., Wimo, A., Guerchet, M., Ali, G. C., Wu, Y., \& Prina, A. M. (2015). World Alzheimer report 2015: The global impact of dementia: An analysis of prevalence, incidence, cost and trends. Alzheimer's Disease International. https://www.alzint.org/resource/world-alzheimerreport-2015/

Qiu, C., von Strauss, E., Bäckman, L., Winblad, B., \& Fratiglioni, L. (2013). Twenty-year changes in dementia occurrence suggest decreasing incidence in central Stockholm, Sweden. Neurology, 80, 1888-1894. https:// doi.org/10.1212/WNL.0b013e318292a2f9
Quintana, M., Anderberg, P., Sanmartin Berglund, J., Frögren, J., Cano, N., Cellek, S., Zhang, J., \& Garolera, M. (2020). Feasibility-usability study of a tablet app adapted specifically for persons with cognitive impairment-SMART4MD (support monitoring and reminder technology for mild dementia). International Journal of Environmental Research and Public Health, 17(18), e6816. https://doi org/10.3390/ijerph17186816

Rathbone, A. L., \& Prescott, J. (2017). The use of mobile apps and SMS messaging as physical and mental health interventions: Systematic review. Journal of Medical Internet Research, 19(8), e295. https://doi.org/10.2196/ jmir.7740

Shuba, N., \& Prakash, B. (2017). Effects of age, gender and education level on cognition in elderly people. Journal of Evolution of Medical and Dental Sciences, 6(95), 69526956. https://doi.org/10.14260/jemds/2017/1509

Sohaib Aslam, A., van Luenen, S., Aslam, S., van Bodegom, D., \& Chavannes, N. H. (2020). A systematic review on the use of mHealth to increase physical activity in older people. Clinical EHealth, 3, 31-39. https://doi. org/10.1016/j.ceh.2020.04.002

Winblad, B., Amouyel, P., Andrieu, S., Ballard, C., Brayne, C., Brodaty, H., Cedazo-Minguez, A., Dubois, B., Edvardsson, D., Feldman, H., Fratiglioni, L., Frisoni, G. B., Gauthier, S., Georges, J., Graff, C., Iqbal, K., Jessen, F., Johansson, G., Jönsson, L., . . Zetterberg, H. (2016). Defeating Alzheimer's disease and other dementias: A priority for European science and society. The Lancet. Neurology, 15(5), 455-532. https://doi.org/10.1016/ S1474-4422(16)00062-4

Woods, R. T., Nelis, S. M., Martyr, A., Roberts, J., Whitaker, C. J., Markova, I., Roth, I., Morris, R., \& Clare, L. (2014). What contributes to a good quality of life in early dementia? Awareness and the QoL-AD: A cross-sectional study. Health and Quality of Life Outcomes, 12, 94. https://doi. org/10.1186/1477-7525-12-94

World Medical Association. (2013). WMA Declaration of Helsinki-Ethical principles for medical research involving human subjects. https://www.wma.net/policies-post/ wma-declaration-of-helsinki-ethical-principles-for-medical-research-involving-human-subjects/ 